\title{
Educação do Campo e Agroecologia: Tecendo conhecimento e construindo saberes na formação profissional do jovem no município de Jaguaré-ES
}

Field Education and Agroecology: Weaving knowledge and building knowledge in the professional formation of young people in the municipality of Jaguaré-ES

Nina Valéria de Araújo Paixão Divina Leila Sôares Silva

Resumo: O presente trabalho tem por objetivo investigar de que maneira a Educação Profissional eTecnológica - EPT alicerçada na Educação do Campo e na Agroecologia vem contribuindo com a transformação social de estudantes da Escola Família Agrícola de Jaguaré no norte do Espírito Santo. Como abordagem metodológica, utilizou-se a pesquisa de carater qualitativo, adotando-se como método empírico a realização de entrevista semiestruturada com estudantes e famílias. Os resultados apontam que, embora genericamente as famílias dos estudantes ainda mantenham traços do manejo convencional com a adoção de insumos agrícolas industrializados, a formação profissional alcançada por meio da Educação do Campo vem possibilitando aos jovens ressignificar as práticas de manejo agrícola praticados em suas unidades produtivas, em vista dos cuidados do solo, de maneira sustentável, contribuindo significativamente com o fortalecimento da agricultura familiar no município.

Palavras-chave: juventude rural; pedagogia da alternância; desenvolvimento local; sustentabilidade; agricultura camponesa.

Abstract: The present work aims to investigate how Professional and Technological Education - EPT based on Rural Education and Agroecology has been contributing to the social transformation of students at Escola Agrícola de Jaguaré in northern Espírito Santo. As a methodological approach, qualitative research was used, adopting a semistructured interview with students and families as an empirical method. The results show that, although the students' families generally still maintain traces of conventional management with the adoption of industrialized agricultural inputs, the professional training achieved through Rural Education has enabled young people to reframe the agricultural management practices practiced in their production units. , in view of soil care, in a sustainable manner, contributing significantly to the strengthening of family farming in the municipality.

Keywords: rural youth; pedagogy of alternation; local development; sustainability; peasant agriculture.

\section{Introdução}

Historicamente, as políticas educacionais apesar dos esforços e avanços, não têm sido suficientemente capazes de contribuir para o desenvolvimento dos povos do campo, das águas e da floresta. Ao contrário, o modelo da nucleação urbana discrimina e promove a dicotomia campo-cidade, e muita das vezes desvaloriza a cultura camponesa e desenraíza os estudantes ao tirá-los do seu 
meio para vir estudar na cidade, "não havendo, nenhuma tentativa de adequar à escola rural às características dos camponeses ou dos seus filhos, quando estes a frequentam" (RIBEIRO, 2012).

É evidente que, ainda nos dias de hoje o modelo tradicional de educação (horizontal e homogêneo) torna-se inadequado para a realidade do campo, visto que o calendário agrícola em geral se "choca" com o calendário escolar, logo, o jovem agricultor se vê diante do dilema entre estudar e ajudar a família com as práticas de manejo agrícola do cotidiano, justamente porque na agricultura familiar o envolvimento de toda a família é de vital importância (NODA, 2006).

Quase sem alternativa muitos desses jovens na tentativa de progredirem nos estudos buscam abrigo em casa de parentes "na cidade" e aos poucos o seu vínculo com a terra vai ficando para trás, sendo este um dos fatores que ainda hoje contribuem com o êxodo rural. Por outro lado, estes jovens, ao abandonarem o seu meio não concorrem em condições de igualdade ao disputar espaços no "mundo urbano", sobretudo, no mercado de trabalho, o que de certa forma ao longo do tempo vem contribuindo para o crescimento desordenado e expansão do processo de favelização em áreas periféricas (CALIARI, 2002 p.42). A respeito deste assunto também Martins (2006, p. 11 apud JESUS, 2011 p.57) descreve:

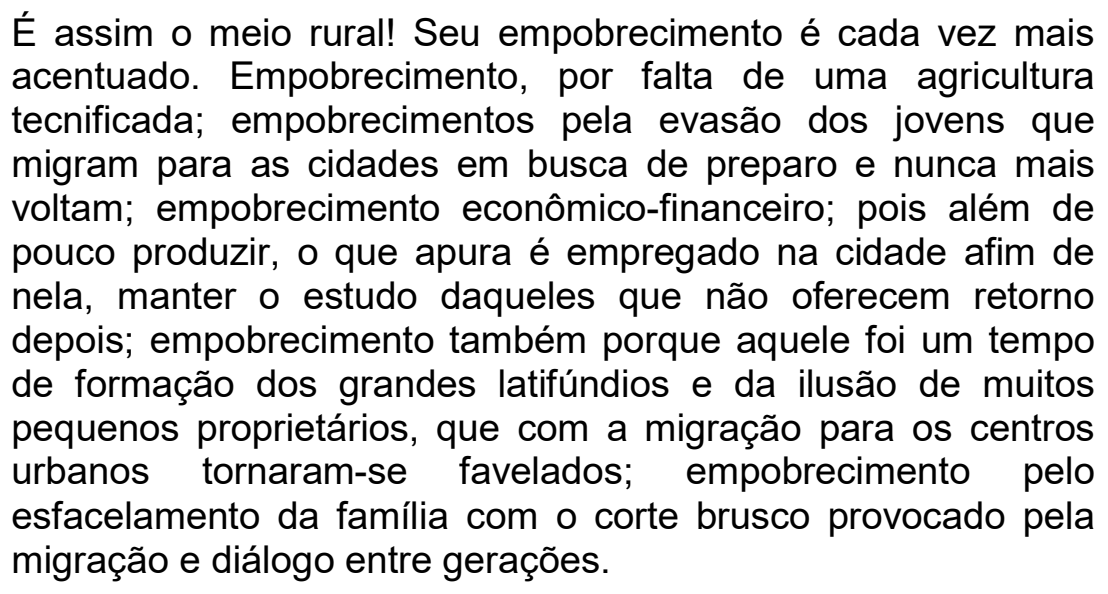

De forma que, se por um lado a educação rural consolidou-se a partir de um projeto criado "para" a população do campo (modo de produção e vida), por outro lado, a educação do campo surgiu como uma proposta de enfrentamento ao modelo existente numa perspectiva contra hegemônica por intermédio dos 
povos do campo, a fim de articular políticas públicas e educacionais que refletem as experiências de resistência camponesa, e que tem delineado contornos inovadores ao modo de pensar a educação para os povos que vivem e trabalham no campo, onde segundo Ribeiro (2012, pág. 298):

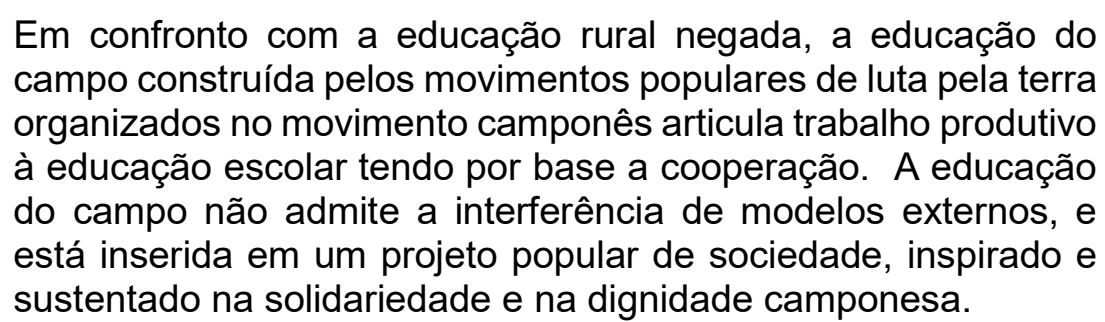

Ao se pensar no território rural como espaço de produção e de vida, por mais que os dois conceitos (educação rural $\mathrm{x}$ educação do campo) a priori assemelham-se, na prática torna-se possível perceber que ambos se distinguem quanto ao processo de emancipação e protagonismo, uma vez que o primeiro vem sendo pensado "para" os povos do campo e o segundo ao longo dos anos vem sendo pensado em consonância com as demandas "dos povos do campo" e que busca historicamente a valorização da cultura campesina.

Advindo dessa inquietação nos deparamos com o desafio que foi se modelando como questão de estudo, sobre como maximizar o conhecimento agroecológico e a valorização dos saberes (integração entre prática e teoria) na formação profissional de jovens camponeses?

Assim, traçou-se como objetivo, investigar de que maneira a Educação Profissional e Tecnológica - EPT alicerçada na Educação do Campo e na Agroecologia vem contribuindo com a com a transformação social de estudantes da Escola Família Agrícola de Jaguaré - EFAJ, no norte do Espírito Santo. Para tanto, se fez necessário identificar como se dá a articulação dos saberes (prático/teórico) na formação integral de jovens camponeses e avaliar de que maneira a formação profissional na educação do campo vem vinculando o processo educativo com a produção no campo e manejo sustentável, e nesse sentido, discutiremos a formação profissional do jovem no contexto educação do campo por meio da Pedagogia da Alternância.

Como abordagem metodológica, utilizou-se a pesquisa de carater qualitativo, adotando-se como método empírico a realização de entrevista 
semiestruturada com estudantes e famílias, favorecendo então uma maior dialogicidade entre os entrevistados e a entrevistadora, além da aplicação de questionário para os professores. Enquanto método teórico, a mesma se deu por meio da abordagem dialética que, segundo Gil (2008) e Minayo (2009), a dialética privilegia as mudanças qualitativas, opõe-se naturalmente a qualquer modo de pensar em que a ordem quantitativa se torne norma.

A coleta de dados ocorreu entre os meses de novembro de 2018 e fevereiro de 2019. Dos sujeitos envolvidos, foram 15 estudantes, 04 pais (representantes da diretoria da Associação Promocional da Escola Família Agrícola de Jaguaré - APEFAJ e do Conselho Fiscal) e 06 professores, totalizando 40 entrevistados. A pesquisa também se pautou no levantamento documental e bibliográfico (livros, teses, Projeto Político Pedagógico - PPP...), bem como na observação cotidiana durante a pesquisa. Para efeito de preservar a identidade dos participantes adotou-se nome de árvores para os estudantes (cujos nomes foram livremente apontados pelos mesmos), nome de aves para as famílias, cuja escolha de nomes ocorreu de forma semelhante aos estudantes e por fim quanto aos professores a identificação se deu a partir dos nomes populares de flores presentes no jardim da EFAJ.

\section{Sobre o tempo e sobre o espaço...}

Para entender melhor o processo de revindicação por uma educação que atendesse aos anseios da população campesina, torna-se importante olhar para trás e refletirmos sobre as causas que ao longo dos anos vem modelando as transformações econômicas e sociais no campo, em detrimento do crescimento da industrialização e expansão dos grandes empreendimentos agrícolas pós Revolução Verde, a respeito desses fatos Jesus (2011 p.56-57) descreve:

O êxodo rural era intenso, muitas famílias estavam deixando suas terras e migrando para os centros urbanos em busca de melhores condições de vida. Por outro lado, crescia o processo de industrialização e a necessidade de mão-de-obra que servisse ao sistema capitalista industrial. [...] A situação no Espírito Santo não era diferente. O crescimento das grandes indústrias como a companhia Siderúrgica de Tubarão e da Aracruz Celulose atraíam pessoas para a metrópole e, em contra partida a erradicação dos cafezais levou agricultores a 
venderem suas terras e a buscarem na cidade alternativas de sobrevivência.

Certamente não podemos fechar os olhos para os grandes projetos que marcaram a história do campesinato capixaba, atrelados ao crescimento industrial. Segundo Jesus (2011), foi diante desse contexto de crise política, êxodo rural acentuado, descrença no campo e precárias condições de acesso à educação que surgiram as primeiras Escolas Famílias no Brasil, adotando a Pedagogia da Alternância ${ }^{1}$ enquanto princípio metodológico, sendo o Espírito Santo o pioneiro na implantação das mesmas no final dos anos 60 , inicialmente no município de Anchieta expandindo-se para o norte do estado nos anos seguintes.

Fruto dessa expansão, a Escola Família Agrícola de Jaguaré tem sua história fundamentada em fatos reais, importantes na sua implantação. Fundada 1972 no norte do Espírito Santo a 203 km da capital Vitória, inicialmente com o curso "Agricultor Técnico", seu contexto de criação está diretamente vinculado à dimensão agrária, social e ambiental do município, assumindo na ocasião um papel de vital importância no processo de resistência ao avanço da monocultura do eucalipto na região, mas foi a partir de 1991 que passou a ofertar o curso Técnico em Agropecuária. (PPP, 2016, p. 9).

A ideia de alternar o tempo escola e convívio familiar possibilitaria o vínculo com a família e associaria os conhecimentos na área da agricultura, fortalecendo a agricultura familiar no município proporcionando o incentivo à permanência desses jovens na sua própria região, por meio de um sistema educativo diferenciado, contribuindo para a preservação do meio ambiente e um desenvolvimento com sustentabilidade, comungando educação básica e a formação profissional que isoladas não são suficientes para transformar o campo, tampouco fortalecem a agricultura familiar.

\footnotetext{
${ }^{1} \mathrm{Na}$ Pedagogia da Alternância o processo de ensino-aprendizagem acontece em espaços e territórios diferenciados e alternados. O primeiro é o espaço familiar e a comunidade de origem (realidade); em segundo, a escola onde o educando (a) partilha os diversos saberes que possui com os outros atores/as e reflete-se sobre eles em bases científicas (reflexão); e, por fim, retornase a família e a comunidade a fim de continuar a práxis (prática + teoria) seja na comunidade, na propriedade (atividades de técnicas agrícolas) ou na inserção em determinados movimentos sociais (Nascimento, 2003).
} 
Apesar da pressão advinda dos grandes empreendimentos e pela busca de mão-de-obra, observa-se que ao longo dos anos a formação profissional que prepare, sobretudo para o mercado de trabalho e não para o mundo do trabalho, não tem sido suficiente para contribuir com o desenvolvimento social do campo. Ao contrário, de acordo com Ribeiro (2012) à medida que grande parte desses jovens ingressam cedo na lida da roça, assim o trabalho produtivo articulado à unidade familiar, associado ao estudo, assume papel essencial no processo educativo quanto ao protagonismo do camponês no campo social.

Reforçando assim, a ideia de que, a organização do trabalho ao longo da história vem sendo alicerçada a partir de uma relação de desigualdade, e de divisão de classes entre o opressor e o oprimido e que de certa forma se refletem no processo educativo ao dicotomizar a relação existente entre o trabalho e a educação, fruto de uma herança histórica da visão do trabalho, em que o trabalho manual era menosprezado em detrimento do trabalho intelectual.

Este entendimento vem ao encontro do que Becevelli (2011) aponta ao dizer:

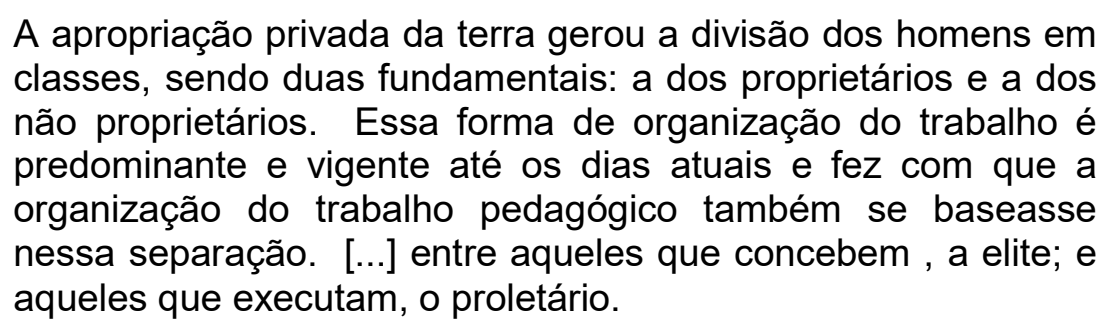

Portanto, é necessário que se veja a educação profissional numa perspectiva emancipatória de maneira integrada a educação básica. É preciso pensar na educação profissional para além da qualificação de mão-de-obra, de forma a potencializar a formação humana, e, sobretudo pensar na formação do sujeito capaz de agir com protagonismo de construir sua própria história, nesse sentido, a valorização de saberes a partir de sua experiência é fundamental no processo educativo.

\section{Fundamentação Teórica}

Com a aprovação do texto final da LDB (Lei no 9.394/96) a educação do campo ganhou um artigo especial que deveria ser transformado nas diversas 
realidades. O Art. 28 prevê que a oferta de educação básica para a educação do campo deve adequar-se às peculiaridades da vida rural, com conteúdos e metodologias adaptadas às necessidades da zona rural, incluindo a adequação do calendário escolar às fases do ciclo agrícola e as condições climáticas.

Diante dessa problemática, a Pedagogia da Alternância, vem construindo um caminho alternativo juntamente com as famílias camponesas por meio de um sistema diferenciado de formação:

A discussão sobre educação do campo no cenário brasileiro nos remete a diferentes iniciativas educacionais que, há algumas décadas, vem se constituindo como alternativa para o homem campesino: as Escolas Comunitárias Rurais, as Casas Familiares Rurais, as os Centros Integrados de Educação Rural (CIER) e entre outras experiências as Escolas Famílias Agrícolas do MEPES (Movimento de Educação Promocional do Espírito Santo), movimento pioneiro na Pedagogia da Alternância na América Latina, com o principal objetivo de promover o homem do campo nas suas diferentes dimensões (JESUS, 2011 p.51).

Numa perspectiva de espaço-tempo de diversidade cultural, social e ecológica a pedagogia da alternância se diferencia também por oportunizar uma formação que permeia a integração dos saberes, de forma peculiar ao ambiente campesino,

A Alternância é uma via pedagógica e metodológica que rompe com as formas tradicionais de fazer escola que se consolida no meio urbano e se expande para as áreas rurais. Ela introduz novos tempos e espaços até então impensáveis na educação brasileira. Transcende o espaço escolar e suas salas de aula, transformando os diversos espaços da comunidade, especialmente o familiar, em espaços de aprendizagem e de produção de saberes. (RACEFFAES, 2015 p. 40)

Nesse alinhavar de conhecimentos e saberes, trabalhar educação do campo dissociado da agroecologia seria minimamente uma contradição, à medida que ambas se consolidaram ao longo de suas existências como ato de resistência contra hegemônico aos moldes de educação, produção e consumo típicos do modelo de capitalista, pautado na transmissão unilateral de conhecimento como forma de alienação,

Daí a conjugação entre educação do campo e agroecologia torna-se primordial à construção de uma educação libertadora 
que proporcione aos camponeses melhorias na qualidade de vida e trabalho. Sendo assim, qualquer forma educativa no campo, seja no âmbito na extensão rural, criação de cursos ou elevação de escolaridade, deve necessariamente integrar os princípios da educação rural e a produção do conhecimento agroecológico, assim como relevar e discutir as práticas e experiências dos agricultores. [...] Assim, na relação educação do campo e agroecologia não ocorre apenas repasse de informações, mas troca e socialização permanente de aprendizados, de práticas conhecimentos e resultados alcançados. A transdisciplinaridade é um dos princípios do processo educativo complexo, que busca construção de conhecimentos pelo domínio de áreas disciplinares relacionadas entre si, tal como a agroecologia (LIMA, 2011 p. 111-122).

Ainda pensando a educação numa perspectiva libertadora, é preciso compreender que a educação profissional reivindicada para a educação do campo embora de maneira geral confundida, ou meramente reduzida à "formação técnica agrícola", agrega um misto de possibilidades, muitas vezes invisíveis aos olhares externos, porém essenciais enquanto direito, a fim de garantir a qualidade de vida no campo enquanto território,

"inclui a preparação para diferentes profissões que são necessárias ao território camponês, cuja base do desenvolvimento está na agricultura - agroindústria, gestão, educação, saúde, comunicação. Etc." - e se relaciona ao acesso dos camponeses à educação e particularmente à educação escolar, incluída nela os cursos de educação profissional (PEREIRA, 2012, p. 286 -292).

Frente a essas possibilidades, no âmbito de garantir uma educação crítica, reflexiva de base emancipatória e, portanto capaz de promover a transformação social, torna-se primordial um projeto educativo articulado com a realidade local, contextualizado às demandas e especificidades do campo, conforme o art. $5^{\circ}$ da Resolução CNE/CEB nº 6 de 2012 (CNE, 2012),

Os cursos de Educação Profissional Técnica de Nível Médio tem por finalidade proporcionar ao estudante conhecimentos, saberes e competências profissionais necessários ao exercício profissional e da cidadania, com base nos fundamentos científicos-tecnológicos, sócio-históricos e culturais. 
Uma educação que forme jovens intelectuais para além da qualificação, e que seja capaz de impulsionar o exercício do protagonismo e da autonomia, como nos aponta Matheus, et. al. (2011, p. 9-24):

A educação básica que não se relaciona com a realidade local e sua diversidade sociocultural não contribui para mudanças profundas nas mentalidades. O campo ou a periferia onde está a agricultura urbana ressente de investimentos públicos na educação escolar e de profissionalização, tanto que os atores coletivos nos fóruns de educação do campo reivindicam educação básica, e superior e não mais investimentos em assistência ao "homem ingênuo ou ignorante" do meio rural [...] compreende-se nessa perspectiva que a juventude atravessa espaços-tempos que requerem processos educativos contextualizados, porque mais do que nunca os jovens necessitam de formação de consciência crítica para instrumentalizar as relações em diversos âmbitos sociais da contemporaneidade.

Nesse sentido, segundo RACEFFAES (2015 p. 106), embora os artigos 36B e 36C da LDB admitam a Educação Profissional Técnica de Nível Médio em dois formatos principais, podendo ser articulada ao ensino médio (integrada ou concomitante) ou subsequente em caso do Ensino Médio já tenha sido concluído, entende-se que, ao se discutir a formação profissional para Educação do Campo, o formato integrado seria o que melhor se ajustaria a realidade camponesa, reafirmando o caráter de formação social e emancipatória contrapondo a dicotomia trabalho intelectual-trabalho manual, advinda de uma relação histórica de subalternização, inerentes dos moldes capitalistas de produção, como bem descreve Frigotto:

Em nossa realidade histórica, a educação politécnica traduz os interesses da classe trabalhadora na crítica à fragmentação dos conhecimentos, à separação entre educação geral e específica, entre a técnica e a política, e a divisão entre trabalho manual e intelectual [...], além disso, afirma "o domínio dos fundamentos científicos das diferentes técnicas que caracterizam o processo de trabalho moderno na relação entre instrução e trabalho" (SAVIANI, 2012, p. 277 apud FRIGOTTO,2003 p.131-152).

Assim, pensar modelos de desenvolvimento para as populações do campo significa antes de tudo contemplá-los em todas as ações e, fundamentalmente ouvi-los para que não sejam reduzidos a "meros objetos da 
ação libertadora que, assim, é realizada mais sobre e para eles do que com eles, como deve ser", como nos aponta a perspectiva de Paulo Freire (1987, p. 79).

\section{Resultados e Discussão}

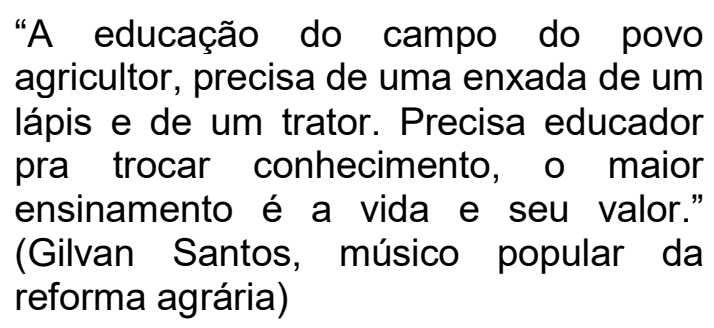

Falar de transformação social de jovens camponeses por meio da educação do campo é, sobretudo compreender de que maneira se dá esse misto experiências e representações sociais. Tal qual uma colcha de retalhos alinhavando-se numa diversidade de saberes que compõe esse processo educativo. É falar não só do lápis que escreve, mas também da enxada que prepara o solo, é juntar a teoria e a prática num processo de sinergia que resulte num germinar de conhecimentos advindos da formação crítica e emancipatória.

Em observações feitas no cotidiano, bem como durante as entrevistas evidenciou-se o gosto dos estudantes por estarem matriculados em uma escola de educação do campo, marcado pelo processo de identidade que os mesmos têm com a instituição:

"Olha, eu vim estudar aqui porque os princípios daqui eu me caracterizo muito né, por ser uma escola do campo, onde minha família também já passou por aqui, e é uma escola que eu me identifico muito". (Jacarandá, 17 anos)

"Minha família toda estudou aqui, além da vontade de fazer o curso técnico né, o curso técnico em agropecuária, eu vejo como, assim, uma contribuição, um processo uma etapa pro futuro, principalmente porque eu quero seguir esse ramo aí da agricultura". (Brejaúba, 16 anos)

Para a maioria dos estudantes, no processo de escolha, não bastava se formar em técnico em agropecuária, o diferencial da formação estava na identidade camponesa evidenciada pelas práticas pedagógicas da escola.

Mas que práticas diferenciadas então seriam essas? Ou de que maneira essa identidade camponesa se torna tão presente no cotidiano da escola? 
Conhecer a história da Escola Família Agrícola de Jaguaré é mais do que conhecer o caminho percorrido por uma instituição é, sobretudo conhecer a trajetória de consolidação da educação do campo no próprio município de Jaguaré. Se por um lado a EFAJ de certa forma foi pioneira no município quanto ao uso de uma pedagogia própria e apropriada para os filhos dos camponeses, ao mesmo tempo ela abriu caminhos para que novas experiências e que hoje são fundamentais para a perpetuação de sua própria existência, visto que:

A região de Jaguaré historicamente vivenciou concretamente
experiências em educação do campo, nas comunidades
camponesas através da Pedagogia da Alternância desenvolvida
pela Escola Família Agrícola de Jaguaré a partir de 1971, nas
ECORM's em 1990 na região do Giral e São João Bosco, na
Escola Estadual do Assentamento XIII de setembro a partir de
1991, no Ensino Fundamental e nas escolas de educação Infantil
em 2000 com o Programa de Valorização da Educação Rural, o
PROVER. Como reconhecimento dessa pedagogia em 1992, O
projeto das Escolas Comunitárias Rurais é reconhecido pela
UNICEF como referência em educação no Brasil. [...] Percebe-
se que há diversas experiências na educação do campo no
município de Jaguaré, sendo essas do ensino fundamental, o
que vem a confirmar a necessidade e a demanda para o curso
Técnico em Agropecuária, ensino médio integrado ao
profissionalizante. (PPP, 2016, p. 8).

Durante as entrevistas ficou evidente essa relação dos estudantes desde as séries iniciais com a educação do campo, e o papel fundamental da EFAJ como uma alternativa de formação profissional alicerçada nos valores camponeses. De acordo as pesquisas documentais, dos 111 estudantes regularmente matriculados na ocasião da pesquisa, $75 \%$ cursaram o ensino fundamental em escolas do campo e mais precisamente em escolas que adotam a pedagogia da alternância enquanto princípio pedagógico, ou seja, das Escolas Comunitárias Rurais Municipais - ECORM's e Escolas de Assentamento:

"Eu nunca estudei em outra escola que não fosse na educação do campo, primeiro estudei na escolinha da roça, sabe aquelas escolinhas multisseriadas, aquela que estuda todo mundo junto e que a professora fala "olha criança esse cantinho do quadro é da $1^{\text {a }}$ série, esse cantinho do quadro é da $2^{\mathrm{a}}$ série...", pois é, depois fui para ECORM, então, vir pra cá era uma consequência, meu pai estudou aqui, meu irmão estudou aqui e minha irmã também, sempre, sempre estudei na pedagogia da alternância, não tive outra formação que não fosse na educação do campo". (Cedro, 17 anos). 
O grande diferencial possivelmente esteja no próprio contexto histórico que resultou na criação da escola advinda do tensionamento, do avanço da monocultura no município e que impulsionou nas comunidades camponesas a busca por um modelo de formação que possibilitasse o fortalecimento da agricultura familiar na região como descreve Oliveira (2018):

A EFA de Jaguaré nasceu em 1972, através da ação da Diocese de São Mateus, do MEPES e Lideranças locais que estavam preocupadas com o êxodo rural e expansão das grandes indústrias, principalmente a Aracruz Celulose e com a carência de uma educação para os jovens rurais. O papel da EFAJ é proporcionar uma educação própria e apropriada do campo, que contribua com o fortalecimento da agricultura familiar em um projeto que valorize e garanta a agricultura camponesa e se integre na construção social de sustentabilidade do campo em nosso país.

E que de acordo com Caldart (2012), a relação de protagonismo dos movimentos sociais camponeses com a educação do campo é o que demarca a essencialidade da própria educação do campo na consciência de mudança nesse sentimento de emponderamento da produção camponesa e que ao longo dos anos vem influenciando no processo de escolhas da juventude camponesa de Jaguaré, ao vincular o processo educativo com a produção no campo e manejo sustentável, o que foi confirmado durante as entrevistas:

"A escola na época tinha os trabalhos social na comunidade de ex-alunos, alunos, monitores e o trabalho era desenvolvido nessa questão de assentamento tudo desenvolvia dentro da minha comunidade e a escola família era que o carro chefe né. [...]Pois é, quando se fala na perspectiva de família e comunidade, o mais interessante que a discussão da escola, o ensino do filho do agricultor ao nível mais alto isso era discutido até dentro das igrejas na celebração se falava a necessidade de levar o filho do agricultor a estudar na escola e se formar voltar esse mesmo filho do agricultor a cultivar a terra dos pais, é você vem, completar o curso e evitar o êxodo rural". (Canário, pai, exestudante e membro da APEFAJ).

"Primeiro veio um colega nosso, um colega meu no caso, né, e veio um ano aí no ano seguinte tinha uns líderes né, que participavam aqui e levavam as propostas da escola pras comunidades né aí na época agente morava lá no Palmitinho e veio um ano antes em 78 aí em 79 eu vim pra cá. É porque o interesse maior era sempre continuar na agricultura e pelo que - aluno daqui ainda levou, era ainda uma das melhores propostas para a agricultura, agricultura familiar, né?! É a 
questão de diversificação de lavouras, né, porque na época a gente tinha era monocultura né, e aí através dele que a gente recomeçou a diversificar a agricultura. O diferencial foi essa mesma situação que eu tô falando, essa questão de você ter um cuidado especial com o meio ambiente né, aonde você convive né, e a questão da própria alimentação mesmo". (Pombo, pai, ex-estudante e membro do conselho fiscal da APEFAJ).

Nesta relação de ensino e aprendizagem, da prática à teoria, a articulação entre três parceiros (família, estudante e monitor) é a base para a construção do conhecimento democrático, é o que permite com que a experiência acumulada pela família contribua na formação do estudante e chegando à escola juntando-se o saber prático ao saber teórico propõe novos significados a construção dos saberes:

"[...] na questão de atividades práticas rurais desenvolvidas foram as práticas de vida desenvolvida pelos trabalhos práticos do meu avô, então meu pai quando chegou nessa linha ele tinha isso pra oferecer pra mim, eu vim buscar mais os estudos conhecimento, as pesquisas que eram desenvolvidas e a escola dá essa capacidade pra você então elevar o conhecimento, só que quando você sai da transformação, igual eu saí da transformação do primário do meu pai pro técnico em agropecuária e voltar essa relação de volta pra família, aí você começa a topar com uma pequena barreira porque essa pequena barreira você tem a capacidade de transformar o conhecimento do seu pai que você é capaz de romper um pouco aquela estrutura que faz, e com as partes técnicas e prática a gente vai conseguir melhorar essa qualidade e fazer um processo de transformação naquilo que ele cultivou na vida inteira, essa foi a $1^{\text {a }}$ barreira que eu topei quando eu voltei em casa, mas eu tinha noção do que eu tava fazendo [...] você tinha que dar o respeito a ele, mas tinha que provar que devagar a gente conseguia fazer um processo de transformação, [...] agora o meu filho já tem o mesmo curso que eu então o que ele consegue é interagir no mesmo nível, ou até melhorar aquilo que já era do meu conhecimento, eu levo pra ele a prática, mas ele ainda já com o passar do tempo os conhecimentos já dele eu considero que hoje, ele conheceu mais pesquisas do que eu conheci na minha época". (Canário, pai, ex-estudante e membro da APEFAJ).

O depoimento de Canário demonstra esse misto de representações, a respeito da importância da família no processo de construção do estudante. $O$ grande desafio dos estudantes enquanto sujeitos é que num primeiro momento não apenas para Canário em sua época, mas para alguns estudantes também nos dias de hoje, é fato de que mesmo que algumas famílias tenham convicção 
das contribuições do curso para a formação dos filhos e para o aprimoramento de práticas na propriedade, ainda assim, por vezes pareciam/parecem demonstrar dificuldades em aceitar as novas contribuições que os filhos possam trazer para propriedade. Mas os saberes nascem assim e amadurecem por meio da contradição e do diálogo, é algo que se perfaz do acúmulo de vivências moldando-se coletivamente, é um longo caminho a ser trilhado.

Outro parceiro fundamental na formação do estudante é o professor/monitor ${ }^{2}$, são atores essenciais na pedagogia da alternância, onde muita das vezes o seu papel ultrapassa as fronteiras da sala de aula, ora orientando estudante, ora atuando como extensionista juntamente às famílias, como verificado no PPP da escola.

Ser monitor da pedagogia da alternância é, sobretudo ter identidade com o projeto, é estar disposto a aprender ao ensinar, é valorizar a vivência do jovem educando em vista de teorizar sua prática claramente elucidada na pedagogia freireana "o educador já não é o que apenas educa, mas o que, enquanto educa é educado, em diálogo com o educando que, ao ser educado, também educa". (FREIRE, 1987, p.68)

Durante as entrevistas foi possível constatar como na prática dos momentos de estudos se dá esse processo de dialogogicidade, tão essencial na educação crítica e emancipatória:

"Essa articulação acontece com certa desenvoltura adquirida ao
longo de sua vivência e experiência obtida durante o curso,
sendo em estágios, visitas e viagens de estudos, convívio com
os colegas etc. São aspectos que proporciona a relação dos
saberes". (Bourgaivillea)
"O Plano de Estudo é o principal meio de articulação do estudo
prático-teórico. Ação-Reflexão / Sessão-Estadia)". (Girassol)

Nessa dinâmica entre sessão e estadia evidencia-se essa articulação dos saberes, onde o estudante vivência sua prática tanto com a família como também

\footnotetext{
2 Monitor, segundo NOSELLA (2014, p. 31), "O professor é chamado de monitor para significar que seu papel vai além da docência implicando o acompanhamento do aluno não apenas em suas atividades escolares, mas também em sua vida social e profissional". Mais recentemente Telau (2015) conceituou como a nomenclatura utilizada para designar os educadores dos Centros Familiares de Formação por AlternÂncia-CEFFA
} 
na comunidade e que contribui significativamente com a formação integral do jovem como mostra Oliveira (2018, p.11):

\begin{abstract}
A Pedagogia da Alternância caracteriza-se, portanto, de uma formação de períodos alternados de vivência e estudos na escola e na família no seu meio sócio profissional acompanhados pelos monitores e pelos pais, garantindo a formação integral do jovem e a aplicação dos instrumentos pedagógicos que são próprios e apropriados.
\end{abstract}

Dentre os instrumentos pedagógicos aplicados pela Pedagogia da Alternância por vezes citado pelos monitores durante as entrevistas, destaca-se o Plano de Estudos, uma ferramenta fundamental nessa dinâmica de troca e construção de saberes, que segundo Telau (2012) trata-se de um método e ao mesmo tempo de um princípio da Pedagogia da Alternância e que proporciona ao estudante a reflexão de sua prática instigando-o não só a problematização, como também por meio da delimitação de novas hipóteses a busca por soluções alternativas ao problema levantado.

Nos CEFFAS, é por meio do plano de estudos que se concretiza a dinâmica do ensino a partir da realidade, ou melhor, dizendo "da prática à teoria". Da vivência da pesquisadora com os estudantes, por diversas vezes observouse algo que merece ser discutido, trata-se do interesse do estudante em aprender algo que ele vê significado, quando se estuda geometria espacial, por exemplo, o que ganha significado naquele momento é o espaçamento entre plantas e o dimensionamento de plantio, é algo que ele traz da vivência que ganha nova nuance quando se teoriza esse saber prático, um conhecimento agropecuário que se discute nas aulas de matemática, o conhecimento assim não é estático, é algo dinâmico e construído de maneira transdisciplinar, nas diferentes áreas de conhecimento e que foi confirmado pelas respostas dos professores/monitores durante a pesquisa:

Exatas por exemplo pode ser usadas na construção de mapas, escalas, calculo de área de plantio, irrigação, calcular a vazão de uma irrigação. (Beldroega).

Proporcionando o estudante compreender que a partir de sua realidade a história da formação é uma colcha de retalhos, aonde o mesmo vai ligando pedacinhos, somando saberes, 
construindo conhecimento, todos os seres são dignos de respeito e somos responsáveis pela vida. (Bourgaivillea)

O resultado da junção desses "pedacinhos" é o que dá consistência a formação integral do jovem, onde o conhecimento técnico não se sobrepõe ao conhecimento prático, e que somando-se às vivência com tradições culturais e sociais tudo contribui com a consciência crítica do estudante, projetando por meio do currículo e dos instrumentos pedagógicos sujeitos de transformação que assimile a realidade recriando-a, enquanto sujeito crítico capaz de escrever e reescrever sua própria história e que de acordo com o PPP (2016) busca-se desenvolver continuamente as potencialidades humanas, de modo a respeitar e valorizar os saberes do educando (Freire, 2018).

Mediante a realidade dos estudantes aqui discutida, tanto no convívio com a família na estadia, quanto na escola durante a sessão, destacam-se três pilares principais ao se pensar na formação profissional de jovens camponeses: a articulação entre o ensino e o trabalho, numa perspectiva do trabalho enquanto princípio educativo, o conhecimento agroecológico enquanto fundamento de resistência da agricultura camponesa, e a integração entre a prática e a teoria.

A maioria dos estudantes da EFAJ são filhos de camponeses e enquanto filhos de camponeses observa-se que a relação entre o trabalho e estudo é algo que se consolida na vida desses estudantes ainda muito cedo, na lida cotidiana da roça, onde de acordo com Mészáros (2008), ao pensar a educação na perspectiva da luta emancipatória, não poderia senão restabelecer os vínculos tão esquecidos entre educação e trabalho e que as entrevistas demonstraram o diferencial do trabalho não no aspecto da exploração/alienação, mas no sentido de demandar a construção de uma consciência crítica:

"Eu tomo as decisões juntamente com meu pai e agente sim reflete muito pensa nas consequências e nos resultados que podem estar acarretando o nosso trabalho [...] Olha, isso agente toca mais quando a gente tá lá no campo que passa toda uma visão do que agente aprendeu aqui, e o que agente exercita lá, e é assim uma coisa muito legal porque a gente sabe que o momento que agente viveu aqui não esquece nunca e que todas as atividades que realizamos aqui, a gente realiza lá também". (Jacarandá, 17 anos).

"Trabalho pra mim é mais uma garantia, um conhecimento daquilo que eu ainda não aprendi, é mais uma forma de 
aprendizado e de contribuição na renda também. Porque o que eu aprendo de conhecimento aqui sobre as culturas aqui na escola eu posso colocar na prática na lavoura lá de onde eu trabalho, e com a prática que eu também tenho lá eu posso colocar em comum aqui na escola". (Paraju, 19 anos).

"Trabalho é sobreviver, é conseguir financeiramente se estabelecer. Eu sou crítica e reflexiva, principalmente lá na roça, quando a gente tá lidando lá com a lavoura, se tem alguma coisa que eu posso melhorar e que eu aprendi na escola eu tenha conhecimento eu coloco a proposta". (Cedro, 17 anos).

"Trabalho, trabalho pra mim, olha, tanto na escola quanto em casa é uma atividade educativa pai ensina a gente que trabalho dignifica a pessoa e mãe também sempre passou isso, não são pessoas que tem informação estudaram até a $4^{a}$ série, no entanto deixam que a gente estude e preza o estudo da gente, meu pai é agricultor, minha mãe da faxina na casa das pessoas e trabalha na roça também ela não sente vergonha disso e eu também não sou digno de tá sentindo vergonha disso, trabalho pra mim é a dignidade". (Angelim-Pedra, 18 anos).

Evidenciando portanto, que o trabalho ao ser potencializado como princípio educativo com o intuito de fortalecer a consciência crítica, ainda durante o curso vem a fomentar no estudante o exercício do protagonismo preparandoo para agir no mundo do trabalho enquanto sujeito e não como objeto.

A pesquisa também demonstrou que, embora os estudantes ao ingressarem na EFA, passam a ter uma nova dimensão sobre o papel da agroecologia na produção sustentável, muitas famílias ainda apresentam dificuldades em implementar em suas realidades um sistema de produção agroecológico, talvez por essa relação de dependência opressora advindas do modo de produção capitalista. No entanto, mesmo não se tornando totalmente agroecológicas, passam a partir dessa vivência a inserir técnicas de conservação do solo e da água, que vem a minimizar o uso de agrotóxicos, e mudar a realidade de muitos agricultores, tanto no aspecto da soberania alimentar, como na geração de renda, diversificação da propriedade, e qualidade de vida. Essas contribuições ficaram evidentes quando questionados sobre conhecimento agroecológico e as mudanças que esse conhecimento proporcionou ao jeito de produzir na unidade produtiva da família:

"A agroecologia é um meio que visa agricultura orgânica, as ações humanas os meios sociais, econômicos e políticos que venha preservar o nosso meio, onde vivemos. O que mudou?! 
É, foi a maior adaptação de práticas, né na nossa unidade produtiva lá, que a gente teve a possibilidade de estar aprendendo aqui. [...]Hoje consigo aplicar o manejo com o mato, o sistema de plantio em morro com curva de nível é, e também em uma pequena área consegui efetuei lá o terraceamento, fiz a adubação com matéria morta e agente assim evita de tá utilizando muito índice de agrotóxico". (Jacarandá).

Se por um lado o modelo capitalista e ocidental se sustenta no antagonismo entre o homem e a natureza, por outro lado, diante dos desafios climáticos a adoção de praticas agroecológicas é essencial para a conservação da água e do solo, uma vez que tanto a população do campo como da cidade é totalmente dependente dos recursos gerados no campo. A agroecologia nesse sentido deixa de ser uma necessidade e assume o papel de condição para a sustentabilidade produtiva, na perspectiva da construção de um novo campo, campo este hoje ainda muito dependente do sistema capitalista (TONAR e GUHUR, 2012).

A construção de uma nova consciência de certa forma, ainda que timidamente, tem promovido a transformação de uma realidade antes marcada pelo êxodo rural, muito influenciada pelo avanço da monocultura e o uso indiscriminado de defensivos químicos. Ao conversar com as famílias nota-se que as mudanças atravessaram as porteiras da propriedade, irradiando-se nas comunidades camponesas contribuindo, portanto com o fortalecimento da agricultura familiar no município:

"Olha eu acredito que pro município foi uma das melhores conquistas que teve né, hoje tem bastante ex-aluno né no meio rural, devido ter estudado aqui, [...] então, pra minha família mesmo principalmente, ela só veio reforçar aquilo que a gente sempre buscava, a questão de você tá na roça, você produzir seu próprio alimento né, e o melhor cuidado que você pode ter com meio ambiente né, então isso aí pra gente foi uma das conquista que a gente defendeu e defende". (Pombo).

"Eu tiro pela nossa propriedade, meu pai sempre trabalhou com agricultura de subsistência e café maduro, na época não se pilava café, se vendia maduro, colhia e vendia toda exploração em cima da agricultura, na pecuária de subsistência também não conseguia se desenvolver muito e a partir do conhecimento técnico se pega as origens da propriedade, não só eu como exaluno, mas de outros ex-alunos da região, houve um processo de transformação, a minha região você pega a raiz da história, se passou por pecuária, se passou por pequenos produtor de 
café e também por plantio de feijão, na época Jaguaré se produzia feijão igual se produz café, mas o ciclo do tempos das águas, da seca foram se modificando então se tinha colheitas garantidas porque chovia produzia, depois tinha período que se perdia com chuva, depois teve o tempo que a falta de chuva começou então a diminuir e parar de produzir, então a transformação ela veio ocorrendo ao longo dos anos, mas a transformação maior que é tirar essas propriedades pequenas duma subsistência e fazer um processo de transformação mesmo que a agricultura é pequena, hoje tem propriedades rurais do município de Jaguaré dentro da minha região que o modelo de produção é muito grande em relação do que já foi no passado, então eu acho que o curso fez essa diferença, a minha comunidade é um exemplo disso. Se você pegar todas as famílias da comunidade e puxar a raiz você vai ver que a maioria dos técnicos em agropecuária toca suas atividades sem depender de agrônomos dessas coisas. Na verdade Jaguaré se tornou uma potencia e a agricultura é o forte da potencia de Jaguaré, sempre foi no passado e a agricultura familiar, a agricultura técnica em agropecuária formada por essa escola eu falo, que é responsável por mais de $75 \%$ do município do sucesso do município em termo de agricultura, [...] Essa contribuição ela é muito forte, ela é muito importante, porque quando você parte pra um curso técnico, e você já carrega na sua bagagem um certo conhecimento de vida prática, é uma alavancada na frente de quem não tem isso". (Canário).

"Pra mim já muda bem, muito... Uma que eu posso ser beneficiado com o conhecimento, porque mesmo que você tá na terra dia a dia, nunca é como você estudar e ter uma orientação mais profunda né. E eu consigo isso e vejo essa ação dos meninos me ajudando lá na minha propriedade. [...] Foi através dos meninos que eu comecei trabalhar dessa forma aí, do mais velho que na época já era formado, mudamos um jeito de trabalhar, hoje eu tenho uma roça bem melhor do que a roça que trabalha com os produtos convencionais brutos, eu falo bruto porque são produtos que às vezes tem que ser usado três vezes ao ano na terra né, e eu não uso nenhum e eu tenho a minha roça que combate ali e produz uma faixa de 80 sacas por hectare, é pequeno, mas já a dele chegou a atingir 82 e a minha atingiu 80 , mas sem o tanto de produto, mas no manejo de sempre capinar a linha e deixar o meio com um pouco mais de matéria".(Guaturama).

Essas mudanças são percebidas pelos estudantes e ficou evidente durante as entrevistas, o protagonismo de se sentir parte das transformações sociais que ocorrem na família e na comunidade.

"Cara, eu nunca fazia ideia do que era agroecológico, agroecologia, eu vejo que hoje aprimorou bastante a gente vê que hoje aqui em nossa região a principal não tem essa visão 
agroecológica, vai tudo assim monocultura, utilizando assim insumos químicos nada visando o bem estar das pessoas, tudo visando a lucratividade entende?! $E$ isso $O$ negócio agroecológico ajuda bastante assim nesse meio a diversificação, a agricultura familiar, na saúde... Influenciou bastante, antes de eu entrar na escola eu tinha a visão de mexer com monocultura...". (Flamboyant).

"Com certeza, porque eu acho que o conhecimento a gente na posse dele a gente pode ir muito longe, e transformar muito a realidade da gente. Agroecologia é uma coisa muito fluente, que ela flui você tendo um ponto de partida você consegue propagar fácil pela influencia e eu acho que eu levando isso tendo a possibilidade de levar isso para dentro da minha realidade eu posso tá propagando para outras pessoas. [...] Cobertura morta, eu ensinei a eles por isso aconteceu mais a redução de agrotóxicos lá na propriedade, em vez de tá passando aquele tipo de agrotóxico no mato fazer a roçagem lá como cobertura, pra tá oferecendo nutrientes. O plantio de culturas pra roçagem eles não fizeram, eles usam somente o mato das culturas espontâneas mesmo. (Angelin-Pedra).

O que prova que a formação integral permite ao estudante uma formação para além da leitura, ela interfere no papel que o estudante passa a assumir na sociedade conforme aponta Oliveira (2018, p.21):

A EFA não é uma escola que está somente preocupada a ensinar o filho do agricultor a ler e a escrever, ela contribui e proporciona aos jovens uma formação integral e global, como também, um desenvolvimento permitindo-os a questionar, refletir e agir sobre a nossa realidade local tendo como resultado a qualidade e a dignidade de vida no campo.

Os professores/monitores ao serem questionados durante as entrevistas sobre as contribuições da formação profissional para a transformação social dos jovens camponeses, foram bastante enfáticos quanto à construção de uma consciência crítica em vista do protagonismo do jovem:

"Através do exercício do protagonismo, da formação integral que perpassa na vida estudantil e intensifica com a maturidade e vivência na prática desenvolvida em seus projetos enquanto jovens camponeses. Pois essa formação contribui também com a criticidade e compromisso na sociedade cidadã". (Bourgainvillea).

"A formação profissional aguça no estudante o sentimento de pertença e a responsabilidade de fazer/desenvolver suas atividades práticas com ciência de que podem fazer melhor, no sentido ecológico, humano e sustentável". (Ixora) 
Os depoimentos dos professores reforçaram esse poder transformador que a educação assume ao educar para a vida, para a ação/reflexão, capaz de promover na vida do estudante a transformação de sua própria realidade.

Diante da abordagem do tema e da problematização que traçou os caminhos dessa pesquisa, compreende-se que seja fundamental trazer ao debate o papel da agroecologia enquanto condição de resistência da agricultura camponesa.

\section{Considerações Finais}

Assim, a problemática a respeito de como maximizar o conhecimento agroecológico e a valorização dos saberes na formação profissional de jovens camponeses, nos inflama a diferentes inquietações das quais se destaca a de é necessário fortalecer o debate a respeito da formação profissional, sobretudo no que tange a juventude do campo, onde articulam questões culturais, ambientais, econômicas e políticas e a educação do campo encontra-se nesse amalgamado de evidencias da complexidade e peculiaridade do campo enquanto território.

A pesquisa nos aponta que, embora genericamente as famílias dos estudantes ainda mantenham traços do manejo convencional, a formação profissional alcançada por meio curso técnico em agropecuária vem possibilitando aos jovens ressignificar as práticas de manejo agrícola executado sem suas unidades produtivas, em vista dos cuidados com o solo, na busca por um jeito mais sustentável de se trabalhar com a terra, contribuindo significativamente com o fortalecimento da agricultura familiar no município. Não há como desvincular essa mudança de paradigma da formação integral proporcionada pela práxis pedagógica da EFAJ, à medida que, fomentar uma educação crítica e emancipatória, é sem dúvida um dos principais caminhos para impulsionar no jovem o exercício do protagonismo, onde o trabalho como princípio educativo associado à integração de saberes exerça sem dúvidas um papel fundamental no caminho para emancipação.

Da educação do campo, do ensino à realidade, há de brotar a semente para liberdade. (Joison Jr. Egresso da EFAJ). 


\section{Referências}

BECEVELLI. I. R. S. Organização do Trabalho pedagógico na EPT: Desafios e Possibilidades. Diálogos sobre a educação profissional e tecnológica: saberes, metodologia e práticas pedagógicas. Disponível em https://ava.cefor.ifes.edu.br/pluginfile.php/123623/mod resource/content/1/POS EPT Artigo completo WEB-cap11 Indiana OPT - 2015.pdf. Acesso em 15 de abril de 2018.

BRASIL. Lei $\mathbf{n} \cdot{ }^{\circ 9} \mathbf{9}$ 394/96, de 20 de dezembro de 1996. Brasília, DF, disponível em http://www.planalto.gov.br/ccivil 03/LEIS//9394.htm, acesso 08/07/2018.

CALDAT, R. S. Educação do Campo. Dicionário da Educação do Campo. São Paulo: Expressão Popular, 2012.

CALIARI, R. O. Pedagogia da Alternância e Desenvolvimento Local. Dissertação (Mestrado em Administração). Universidade Federal de Lavras. Lavras, 2002.

FREIRE, P. Pedagogia do Oprimido, Rio de Janeiro: Paz e Terra, 1987.

Pedagogia da Autonomia: Saberes Necessários à Prática Educativa. 57ª ed. -Rio de Janeiro/São Paulo: Paz na Terra, 2018.

FRIGOTTO, G. Educação Politécnica. Dicionário da Educação do Campo. São Paulo: Expressão Popular, 2012.

GIL, A. C. Métodos e Técnicas de Pesquisa Social. 6. ed. - São Paulo: Atlas, 2008.

JESUS, J. G. Formação dos Professores na Pedagogia da Alternância: Saberes e Fazeres do Campo. Vitória: GM, 2011.

LIMA, F.O. Educação e Agroecologia: Tecendo relações. In: Cadernos de discussão: juventude, educação do campo e agroecologia. Rio de Janeiro: Outras Letras, 2011.

MATHEUS, A. C. et. al. Juventude Protagonizando a Transição Agroecológica no Estado do Rio de Janeiro: Experiência da Intervivência Universitária na UFRRJ. In: Cadernos de discussão: juventude, educação do campo e agroecologia. Rio de Janeiro: Outras Letras, 2011.

MEPES. Processo de renovação de oferta de curso. Curso Técnico em Agropecuária Integrado ao Ensino Médio, Eixo Tecnológico Recursos Naturais na Escola Família Agrícola de Jaguaré. Resolução CEE n 3.807/2014 D.O. 08/07/2014 - Jaguaré-, 2014.

MÉSZÁROS, I. A Educação para Além do Capital. 2a ed. - São Paulo: Boitempo, 2008.

MINAYO, M. C. S. (Org.) Pesquisa Social: Teoria, método e criatividade. 28 ed. - Petrópolis: Vozes, 2009. 
NASCIMENTO, C. G. Pedagogia da Resistência Cultural: Um pensar a educação a partir da realidade campesina. In: VIII Encontro Regional de Geografia (EREGEO). Goiás: 2003.

NODA, S. do N., NODA, H. e MARTINS, A. L. U. Agricultura Familiar na Várzea Amazônica: Espaço de conservação da diversidade cultural e ambiental. In: Amazônia: Políticas públicas e diversidade cultural. Rio de Janeiro: Garamond, 2006.

NOSELLA, P. As Origens da Pedagogia da Alternância no Brasil. Coleção Educação do Campo, 2a Reimpressão, Vitória: EDUFES, 2014.

OLIVEIRA, E. Da Teoria à Prática: Um estudo sobre o projeto profissional do jovem da Escola Família Agrícola de Jaguaré-ES. Seropédica: UFRRJ, 2018. Dissertação (Mestrado em Educação) Programa de Pós-Graduação em Educação Agrícola, Universidade Federal Rural do Rio de Janeiro, 2018.

PEREIRA, I. B. Educação Profissional. Dicionário da Educação do Campo. São Paulo: Expressão Popular, 2012.

PPP. Projeto Político Pedagógico da Escola Família Agrícola de Jaguaré. Jaguaré, 2016.

RACEFFAES: Regional das Associações dos Centros Familiares de Formação em Alternância do Espírito Santo: Cultivando A Educação dos Povos do Campo do Espírito Santo. São Gabriel da Palha, ES: [sn], 2015.

RIBEIRO, M. Educação Rural. Dicionário da Educação do Campo. São Paulo: Expressão Popular, 2012.

TELAU, R. A Importância do Plano de Estudo - a metodologia da Pedagogia da Alternância - na formação dos estudantes do $9^{\circ}$ ano da Escola Municipal Comunitária Rural Padre Fulgêncio do Menino Jesus. Projeto de Pesquisa e Experimentação Pedagógica - Especialização em Pedagogia da Alternância e Educação do Campo, Universidade Federal de Minas Gerais, 2012.

Ensinar - Incentiva - Mediar: Dilemas nas formas de sentir, pensar e agir dos educadores dos CEFFAs sobre os processos de ensino/aprendizagem. Belo Horizonte: UFMG, 2015. Dissertação (Mestrado em Educação), Universidade Federal Ruralo de Minas Gerais, 2015.

TONAR, N.; GUHUR, D. M. Agroecologia. Dicionário da Educação do Campo. São Paulo: Expressão Popular, 2012.

\section{Sobre as autoras}

Nina Valéria de Araújo Paixão

nina.agro@hotmail.com

Graduação em Agronomia pela Universidade Federal Rural do Rio de Janeiro UFRRJ (2010) e Especialização em Educação Profissional e Tecnológica pelo 
Instituto Federal de Educação, Ciência e Tecnologia do Espírito Santo - IFES (2019). Educadora, Coordenadora do Curso Técnico em Agropecuária e Coordenadora de Estágio Supervisionado na Escola Família Agrícola de Jaguaré - MEPES.

\section{Divina Leila Sôares Silva}

divinaleila@ifes.edu.br

Possui graduação em Pedagogia pela Faculdade Castelo Branco (1987) e mestrado em Educação pela Universidade Federal do Espírito Santo (2013). Atualmente é Pedagoga-Supervisora Educacional do Instituto Federal de Educação, Ciência e Tecnologia do Espírito Santo, sendo que desde 2013 encontra-se à frente da Diretoria de Ensino do Campus Colatina. Tem experiência na área de Educação, atuando principalmente nos seguintes temas: formação de professores, educação infantil, trabalho docente, atuação docente e carreira docente. 